\title{
Hemşirelerde Koronafobi
}

\section{Coronaphobia in Nurses}

\author{
${ }^{1}$ Burcu DEMIR GÖKMEN, ${ }^{2}$ Yılmaz SARIBOĞA \\ ${ }^{1}$ Ağrı İbrahim Çeçen Üniversitesi, Sağlık Yüksekokulu, Hemşirelik Bölümü Ağrı/Türkiye \\ ${ }^{2}$ SBÜ Van Eğitim ve Araştırma Hastanesi, Kardiyoloji Yoğun Bakım Kliniği, Van/Türkiye \\ Burcu Demir Gökmen.: https://orcid.org/0000-0003-2058-8924 \\ Y1lmaz Sarıboğa: https://orcid.org/0000-0001-6348-2797
}

\section{ÖZ}

Amaç: Bu araştırma Türkiye'de bir hastanede çalışan hemşirelerde koronafobi ve bunu etkileyen faktörleri incelemek amacı ile yapıld1.

Materyal ve Metot: Tanımlayıcı türde tasarlanan araştırma 05-12 Şubat 2021 tarihleri arasında yapıldı. Araştırmada kartopu örnekleme yöntemi ile ulaşılabilen, gönüllü 310 hemşire ile çalışıldı. Veriler sosyal ağlar aracılığ 1 ile "Sosyodemografik Bilgi Formu", "Koronavirüs 19 Fobisi Ölçeği" kullanılarak toplandı. Verilerin analizinde sayı, yüzde, ortalama, bağımsız gruplarda t testi, tek yönlü varyans analizi, Kruskall Wallis testi kullanıldi.

Bulgular: Araştırmada kadın olma, dahili kliniklerde çalışıyor olma, gündüz saatlerinde çalışıyor olma, kronik hastalık varlığı, yakınının Covid-19 tanısı alması ve aşılanma durumlarına göre koronafobinin psikolojik alt boyut puanıı daha yüksek olduğu saptandı. Evli, çocuklu olan ve yakınına Covid-19 tanısı konulan hemșirelerde ve Covid-19 sürecinde hemşirelik yapmak isteyen hemşirelerde diğer gruplara göre Koronafobi ve tüm alt boyutları puanlarının yüksek olduğu belirlendi $(\mathrm{p}<0,05)$.

Sonuç: Araştırmada hemşirelerin daha çok koronafobinin psikolojik boyutundan etkilendikleri görülmektedir. Hemşirelerin psikolojik savunmalarını güçlendirmek için psikoeğitime yönelik müdahalelerin yapılması önerilmektedir.

Anahtar Kelimeler: Covid-19, fobi, hemşire

\begin{abstract}
Objective: The study was conducted to examine coronaphobia and the factors affecting it in nurses working in a hospital in Turkey.

Materials and Methods: The descriptive study was conducted between 05-12 February 2021. In the study, 310 nurses, who can be reached by snowball sampling method, were studied. The data were collected through social networks using the "Sociodemographic Information Form", "Covid-19 phobia scale". Number, percentage, average, independent in data analysis t test, one-way analysis of variance, Kruskall Wallis test were used in the groups.
\end{abstract}

Results: The study, it was determined that the psychological sub-dimension score of coronaphobia was higher according to being a woman, working in internal clinics, working during daylight hours, presence of chronic disease, being diagnosed with Covid-19 in a relative, and being vaccinated. It was determined that the scores of Coronaphobia and all sub-dimensions were high in nurses who were married, had children and were diagnosed with Covid-19, and nurses who wanted to nurse during the Covid-19 process to other groups $(\mathrm{p}<0.05)$.

Conclusion: The study, it is seen that nurses are mostly affected by the psychological dimension of coronaphobia. The psychological defenses of nurses psychoeducation interventions are recommended to strengthen.

Keywords: Covid-19, nurse, phobia

\section{Sorumlu Yazar / Corresponding Author:}

Burcu Demir Gökmen.

Ağrı İbrahim Çeçen Üniversitesi, SYO, Hemș. Böl. Ağr1/Türkiye

Tel: +90 5067516888

E-mail:burcudmr04@gmail.com
Yayın Bilgisi / Article Info:

Gönderi Tarihi/ Received: 28/02/2021

Kabul Tarihi/ Accepted: 16/07/2021

Online Yayın Tarihi/ Published: 05/09/2021

Atıf / Cited: Demir Gökmen B ve Sarıboğa Y. Hemşirelerde Koronafobi. Online Türk Sağllk Bilimleri Dergisi 2021;6(3):372-381. doi: 10.26453 /otjhs. 888006 


\section{GÍRIŞ}

İnsanlık tarihi boyunca Covid-19 salgını gibi küresel karışıklığa ve paniğe neden olan çok az olayın meydana geldiği görülmektedir. ${ }^{1}$ Bunların çoğunda olduğu gibi koronavirüs ile mücadelede de cephenin ön kısmında hemşirelerde yer almaktadır. Salgın sürecinde hemşireler iş yoğunluğunun ötesinde, yeni protokollere, "yeni olan bir normale" uyum sağlamaya çalışmak, koruyucu ekipmanlarla uzun süre çalışmak, çalışma ortamındaki yetersizlikler, riskli bir gruba bakım veriyor olmak, enfekte olmak, virüsü başkalarına bulaştırmak, hastalarda alışık olduklarından daha hızlı bir bozulmaya tanık olmak, daha sık palyatif bakım sağlamak durumundadırlar. Bu süreci yönetmekte zorlanan hemşirelerde anksiyete, korku, depresyon gibi ruhsal sıkıntıların yaşandı ğ mektedir. $^{2-7}$

Korku; gerçek ya da algılanan bir tehdit varlığında aniden gelişen kaçma davranışına neden olan tepkisel bir duygu durumudur. ${ }^{2}$ Mental Bozuklukların Tanısal ve İstatiksel El Kitabı (DSM-V) kriterlerine göre, durum ve çevre göz önüne alındığında, bireyin orantısız korku ve kaygı tepkisinin yoğun olması fobi tanısı için yeterlidir. Fobiler sosyal fobi, agorafobi ve spesifik fobi olarak üç grupta sınıflandırılmaktadır. Korona fobisi spesifik fobiler kapsamında değerlendirilmektedir. Covid-19 salgını insanların yaşam döngüsünü değiştirdiğinden anksiyete ve fobik bozukluklara neden olmaktadır. ${ }^{8,9}$

Hemşirelerin Covid-19'un beraberinde getirdiği zorluklara karşı ellerinden gelenin en iyisini yapmaya çalıştıkları gözlenmektedir. ${ }^{10}$ Öyle ki 2020 yılı hemşirelerin koronavirüsle savaştığı bir yıl olmuştur. Hemşirelerin korkuya kapılmadan çalışmaları için, öncelikle gereksinimleri anlaşılmalıdır. Bu doğrultuda hemşirelerin ruhsal sağlığını koruma ve arttırmaya yönelik yaklaşımlar geliştirilebilir. Hemşirelerin ruhsal sorunlar yaşaması sağlık hizmetlerinin sunumunu olumsuz etkileyebilir. Hemşirelerden verdikleri hizmeti en iyi şekilde sürdürmeleri isteniyorsa sağlıklarının da aynı şekilde korunması önemlidir. ${ }^{10}$ Böylece hemşireler çok daha etkin bir biçimde çalışabilirler. ${ }^{3}$ Alan yazında pandemide hemşirelerle yapılan covid-19 korkusuna ilişkin bilgi ve çalışmaların sınırlı olduğu ve sağlık hizmetlerinin geliştirilmesi için daha fazla güncel bilgiye gereksinim olduğu görülmektedir. Yapılan çalışmalarda Covid-19 korkusunun hemşirelerde topluma göre daha yüksek olduğu, korkuyu arttıran faktörün enfekte olma ve bilmeden diğerlerine bulaştırma riskinden kaynaklandığ belirtilmektedir. $^{11-13}$
$\mathrm{Bu}$ araştırma risk altındaki hemşire popülasyonunda koronafobiyi belirlemek ve bunu etkileyen yaş, cinsiyet, çalışılan klinik, çalışma saatleri, kronik hastalık gibi çeşitli etmenleri incelemek amacıyla yapıldı.

\section{MATERYAL VE METOT}

Araştırma için Ağrı İbrahim Çeçen Üniversitesi/ Bilimsel Araştırmalar Etik Kurulundan onay (Tarih: 27.01.2021, karar no:20), Eğitim Araştırma Hastanesinden izin (Tarih: 05.02.2021, sayı no: 1444), Sağlık Bakanlığı Sağlık Hizmetleri Genel Müdürlüğü'nden online olarak araştırma onay (Tarih: 03.02.2021 say1 no:2021-02-08T01_19_02.) ve her bir katılımcıdan bireysel onam alındı.

Tanımlayıcı türde yapılan araştırma, 5-12 Şubat 2021 tarihleri arasında, bir Eğitim Araştırma Hastanesi'nde yürütüldü. Hastanede çalışan hemşirelerin (1248) tamamı araştırmanın evrenini, kartopu yöntemi ile ulaşılabilen tüm hemşireler ise örneklemi oluşturdu. ${ }^{14}$ Örneklem sayısını belirlemek için kullanilan (n: (N.t. $\left.{ }^{2} \cdot p \cdot q\right) /\left(d^{2} .(N-1)+\left(t^{2} \cdot p \cdot q\right)\right)$ formüle göre ulaşılması gereken sayı 296 hemşiredir.

Araştırmada ulaşılabilecek maksimum sayıdaki hemşirelerle çalışma hedeflendi. Araştırmanın amacına uygun olarak hazırlanan formlar çevrim içi ortama aktarılarak, oluşturulan link çeşitli uygulamalar (Watsapp, mail vb) aracılığıyla hemşirelerle paylaş1ldı ve hemşirelerin diğer hemşirelerle paylaşması istendi. Veri artışı günlük olarak takip edildi ve bir hafta sonrasında artış olmadığında süreç sonlandırıld. Araştırmaya toplam 310 gönüllü hemşire katılmiştır.

\section{Veri Toplama Araçları:}

Sosyodemografik Bilgi Formu: Literatür doğrultusunda hazırlanan form, bireylerin tanıtıcı özellikleri ve iş yaşamlarıyla ilgili bilgileri sorgulayan 13 sorudan oluşmaktadır. ${ }^{3,9,10}$

Koronavirüs 19 Fobisi Ölçeği (K19F-Ö): Arpacı ve $\operatorname{ark}^{9}$ tarafından geliştirilen ölçek 20 madde, 4 alt boyuttan oluşan 5'li likert tiptedir. Ölçek; psikolojik $(1,5,9,13,17,20)$ somatik $(2,6,10,14,18)$, sosyal $(3,7,11,15,19)$ ve ekonomik $(4,8,12,16)$ alt boyutlarından oluşmaktadır. Ölçek maddeleri; 1 "Kesinlikle katılmıyorum" ile 5 "Kesinlikle katılıyorum" arasında değerlendirilir. Ölçek toplam puanı alt boyut puanlarının toplamı ile elde edilir ve 20 100 puan arasında değişir. Puanların yüksekliği alt boyutlardaki ve genel koronafobideki yüksekliğe işaret eder. Ölçeğin toplam boyutu ile psikolojik, somatik, sosyal ve ekonomik alt boyutları için sırasiyla Cronbach Alfa değeri; 0,$93 ; 0,88 ; 0,90 ; 0,90$; 
0,85 olarak belirtilmektedir. Bu çalışmada ise sırasıyla Cronbach Alfa değeri; 0,94; 0,85;0,85;0,85; 0,80'dir.

Verilerin Değerlendirilmesi: Veriler SPSS 24 paket programında $\% 95$ güven aralığı ve $\mathrm{p}<0,05$ anlamlılık düzeyinde değerlendirildi. Tanımlayıcı veriler için sayı, ortalama ve yüzde kullanıldı. Verilerin normal dağılım incelemesi ise Kolmogorov-Smirnov testi, Shapiro-Wilk testi ile yapıldı ve ölçeklere ait puanların bazı değişkenler için normal dağılım gösterdiği, bazı değişkenler için ise normal dağılım göstermediği belirlendi. $\mathrm{Bu}$ nedenle normal dağılım gösteren gruplar için parametrik karşılaştırma testlerinden bağımsız gruplarda $t$ testi, tek yönlü varyans analizi (ANOVA) kullanılırken; normal dağılım göstermeyen gruplarda nonparametrik karşılaştırma testlerinden Mann Whitney U testi ve Kruskall Wallis testi kullanıldı.

\section{BULGULAR}

Araştırmaya katılan hemşirelerin sosyodemografik verileri incelendiğinde; \%64,8'inin kadın, \% 39,7'sinin 26-30 yaş aralığında, \%57,1'inin evli, \% 12 'sinin gebe olduğu ve \%50,6'sının çocuk sahibi

Tablo 1. Hemşir eler in sosyodemografik değişkenleri $(n=310)$.

\begin{tabular}{|c|c|c|c|}
\hline \multicolumn{2}{|l|}{ Sosyodemografik Değişkenler } & \multirow{2}{*}{$\begin{array}{c}\begin{array}{c}\text { Sayı } \\
\text { (n) }\end{array} \\
201 \\
\end{array}$} & \multirow{2}{*}{$\begin{array}{c}\begin{array}{c}\text { Yüzde } \\
\text { (\%) }\end{array} \\
64,8 \\
\end{array}$} \\
\hline Cinsiyet & Kadın & & \\
\hline & Erkek & 109 & 35,2 \\
\hline \multirow[t]{4}{*}{ Yaş } & $20-25$ & 47 & 15,2 \\
\hline & $26-30$ & 123 & 39,7 \\
\hline & $31-35$ & 73 & 23,5 \\
\hline & 36 yaş ve üstü & 67 & 21,6 \\
\hline \multirow[t]{2}{*}{ Medeni durum } & Evli & 177 & 57,1 \\
\hline & Bekar & 133 & 42,9 \\
\hline \multirow[t]{3}{*}{ Çocuk sayısı } & 0 & 157 & 50,6 \\
\hline & 1 & 71 & 22,9 \\
\hline & 2 ve üzeri & 82 & 26,5 \\
\hline \multirow[t]{2}{*}{ Gebelik durumu $(n=201)$} & Evet & 24 & 12,0 \\
\hline & Hayır & 177 & 88,0 \\
\hline \multirow[t]{4}{*}{ Görev yaptığı klinik } & Dahiliye klinikleri & 99 & 31,9 \\
\hline & Cerrahi klinikler & 64 & 20,6 \\
\hline & Acil & 51 & 16,5 \\
\hline & Ameliyathane ve yoğun bakım & 96 & 31,0 \\
\hline \multirow[t]{3}{*}{ Çalışma şekli ve saatleri } & Gündüz & 99 & 31,9 \\
\hline & Gece & 43 & 13,9 \\
\hline & Gündüz ve gece & 168 & 54,2 \\
\hline \multirow[t]{2}{*}{ Kronik hastalık durumu } & Var & 61 & 19,7 \\
\hline & Yok & 249 & 80,3 \\
\hline \multirow[t]{3}{*}{ Covid-19 tanısı konma durumu } & Evet & 94 & 30,3 \\
\hline & Hayır & 216 & 69,7 \\
\hline & Var & 191 & 61,6 \\
\hline \multirow[t]{2}{*}{ Yakınınızda kronik hastalık var mı? } & Yok & 119 & 38,4 \\
\hline & Evet & 153 & 49,4 \\
\hline Yakınına Covid-19 tanısı konan var mı? & Hayır & 157 & 50,6 \\
\hline \multirow[t]{2}{*}{ Covid-19 aşılanma durumu } & Evet & 260 & 83,9 \\
\hline & Hayır & 50 & 16,1 \\
\hline \multirow{2}{*}{$\begin{array}{l}\text { Covid-19 sürecine bağlı olarak emşirelik } \\
\text { yapma isteği }\end{array}$} & Hemşirelik yapmak istiyorum & 113 & 36,5 \\
\hline & Hemşirelik yapmak istemiyorum & 197 & 63,5 \\
\hline
\end{tabular}

olmadığ1 görülmektedir. Hemşirelerin \%31,9'unun dahiliye kliniklerinde görev yaptığ 1 , \%54,2'sinin hem gündüz hem de gece saatlerinde çalıştığı, çoğunluğunun (\%80,3) kronik bir hastalığ1 olmadı̆̆ ve Covid-19 hastalığı tanısı konulmadığı $(\% 69,7)$ belirlendi. Hemşirelerin \%61,6'sının birlikte yaşadığı birinci dereceden yakınlarında kronik bir hastalığın bulunduğu ve \%49,4'nün yakınlarının Covid-19 hastalığını geçirdiği görülmektedir. Hemşirelerin çoğunluğunun $(83,9)$ aşı yaptırdığı, \%63,5'inin ise Covid-19 sürecine bağlı olarak hemşirelik yapmak istemediği tespit edildi (Tablo 1).

Araştırmada hemşirelerin koronafobi ölçeği (K19KÖ) ve alt boyutları puan ortalamaları Tablo 2'de 
Tablo 2. Hemşir elerin K19K-Ö'den aldıkları toplam puan ve alt boyutları puan ortalamaları.

\begin{tabular}{|l|c|c|c|}
\hline & \multicolumn{3}{|c|}{ K19K-Ö } \\
\hline Psikolojik Alt Boyut & $\begin{array}{c}\text { Alınabilecek } \\
\text { Min-Max }\end{array}$ & $\begin{array}{c}\text { Alınan } \\
\text { Min-Max }\end{array}$ & Ort \pm SS \\
\hline Somatik Alt Boyut & $6-30$ & $7-30$ & $22,08 \pm 6,07$ \\
\hline Sosyal Alt Boyut & $5-25$ & $5-25$ & $11,95 \pm 5,51$ \\
\hline Ekonomik Alt Boyut & $5-25$ & $5-25$ & $16,13 \pm 5,63$ \\
\hline Toplam Puan & $4-20$ & $4-20$ & $9,35 \pm 4,24$ \\
\hline
\end{tabular}

K19K-Ö: Koronofobi ölçeği; Min: En küçük puan; Max: En büyük puan; ort: Ortalama; SS: Standart sapma.

gösterilmektedir. Hemşirelerin Koronafobi ölçeğinden toplamda 59,51 $\pm 19,14$ puan aldıkları ve K19KÖ’nin psikolojik alt boyutundan 22,08 $\pm 6,07$ puan, somatik alt boyutundan $11,95 \pm 5,51$ puan, sosyal alt boyutundan $16,13 \pm 5,63$ puan ve ekonomik alt boyutundan ise 9,35 $\pm 4,24$ puan aldıkları tespit edildi. K19K-Ö değerlendirilirken puanlaması 20 ile 100 puan arasında değişmekte ve alınan toplam puan ve alt boyutları puanlarının yüksekliği koronafobinin de arttığını göstermektedir. Bu durumda hemşirelerin koronafobi toplam puan ortalamasının orta düzeyde olduğu söylenebilir. K19K-Ö’nin psikolojik alt boyutu puan ortalamasının diğer alt boyutları puan ortalamalarına göre daha yüksek olduğu görülmektedir.

Araştırmada hemşirelerin sosyodemografik değiş- kenler ile K19K-Ö ve alt boyutlarının puan ortalamaları karşılaştırması Tablo 3'de verildi. Hemşirelerin cinsiyet değişkenine göre K19K-Ö alt boyutları puan ortalamaları incelendiğinde; K19K-Ö'nin psikolojik alt boyutu puan ortalamasının kadınlarda $22,86 \pm 5,54$, erkeklerde ise $20,63 \pm 6,73$ olduğu görülmektedir. Gruplar arasındaki puanların istatistiki açıdan anlamlı farklılık oluşturduğu kadınların erkeklere oranla yüksek puan aldığı belirlendi $(\mathrm{p}<0,05$, Tablo 3).

Araştırmada hemşirelerin medeni durumlarına göre K19K-Ö toplam puan ortalamasına bakıldığında; K19K-Ö toplam puan ortalaması evlilerde $61,76 \pm 18,93$, bekarlarda ise $56,51 \pm 19,07$ 'dir. K19K -Ö alt boyutları ise; K19K-Ö’nin somatik, sosyal ve ekonomik alt boyutu ortalama puanlarının sirasıyla

Tablo 3. Hemşirelerin sosyodemografik değişkenlerine göre koronafobi ölçeği'nin toplam puan ortalaması ve alt boyutları puan ortalamaları ile ilgili analizler.

\begin{tabular}{|c|c|c|c|c|c|c|c|}
\hline & & & \multicolumn{5}{|c|}{ K19K-Ö } \\
\hline & & & $\begin{array}{l}\text { Psikolojik Alt } \\
\text { Boyut }\end{array}$ & $\begin{array}{l}\text { Somatik Alt } \\
\text { Boyut }\end{array}$ & $\begin{array}{l}\text { Sosyal Alt } \\
\text { Boyut }\end{array}$ & $\begin{array}{l}\text { Ekonomik } \\
\text { Alt Boyut }\end{array}$ & Toplam Puan \\
\hline Özellikler & $\mathrm{n}$ & $\%$ & Ort. \pm SS & Ort. \pm SS & Ort. \pm SS & Ort. \pm SS & Ort. \pm SS \\
\hline \multicolumn{8}{|l|}{ Cinsiyet } \\
\hline Kadin & 201 & 64,8 & $22,86 \pm 5,54$ & $12,12 \pm 5,43$ & $16,24 \pm 5,54$ & $9,14 \pm 4,07$ & $60,36 \pm 18,02$ \\
\hline Erkek & 109 & 35,2 & $20,63 \pm 6,73$ & $11,63 \pm 5,66$ & $15,93 \pm 5,99$ & $9,73 \pm 4,53$ & $57,93 \pm 21,05$ \\
\hline \multirow{2}{*}{\multicolumn{3}{|c|}{ İstatiksel analiz }} & $\mathrm{U}=8854,0$ & $\mathrm{U}=10230,0$ & $\mathrm{U}=106180$ & $\mathrm{U}=1021,0$ & $\mathrm{t}=1,022$ \\
\hline & & & $\mathrm{p}=0,005^{*}$ & $\mathrm{p}=0,335$ & $\mathrm{p}=0,655$ & $\mathrm{p}=0,324$ & $\mathrm{p}=0,308$ \\
\hline \multicolumn{8}{|l|}{ Yaş } \\
\hline $20-25$ & 47 & 15,2 & $21,85 \pm 6,40$ & $10,96 \pm 5,35$ & $14,66 \pm 5,51$ & $8,36 \pm 4,18$ & $55,83 \pm 19,11$ \\
\hline $26-30$ & 123 & 39,7 & $21,50 \pm 5,85$ & $11,47 \pm 5,08$ & $15,83 \pm 5,33$ & $9,02 \pm 3,94$ & $57,81 \pm 17,65$ \\
\hline $31-35$ & 73 & 23,5 & $22,51 \pm 6,09$ & $12,44 \pm 5,87$ & $16,63 \pm 5,85$ & $6,67 \pm 4,27$ & $61,25 \pm 19,84$ \\
\hline 36 yaş ve üstü & 67 & 21,6 & $22,84 \pm 6,21$ & $13,00 \pm 5,86$ & $17,16 \pm 6,13$ & $10,30 \pm 4,63$ & $59,51 \pm 19,14$ \\
\hline \multirow{2}{*}{\multicolumn{3}{|c|}{ İstatiksel analiz }} & $\mathrm{KW}=3,473$ & $\mathrm{KW}=5,008$ & $\mathrm{KW}=6,065$ & $\mathrm{KW}=7,154$ & $\mathrm{~F}=1,99$ \\
\hline & & & $\mathrm{p}=0,324$ & $\mathrm{p}=0,171$ & $\mathrm{p}=0,109$ & $\mathrm{p}=0,067$ & $\mathrm{p}=0,115$ \\
\hline \multicolumn{8}{|l|}{ Gebelik durumu } \\
\hline Evet & 24 & 12,0 & $23,83 \pm 4,74$ & $13,67 \pm 5,66$ & $17,42 \pm 4,52$ & $10,50 \pm 4,01$ & $65,42 \pm 17,37$ \\
\hline Hayır & 177 & 88,0 & $22,80 \pm 5,59$ & $12,03 \pm 5,42$ & $16,16 \pm 5,60$ & $9,05 \pm 4,07$ & $60,04 \pm 18,06$ \\
\hline \multirow{2}{*}{\multicolumn{3}{|c|}{ İstatistiksel analiz }} & $\mathrm{U}=1038,5$ & $\mathrm{U}=903,0$ & $\mathrm{U}=989,5$ & $\mathrm{U}=868,5$ & $\mathrm{U}=921,5$ \\
\hline & & & $\mathrm{p}=0,624$ & $p=0,236$ & $\mathrm{p}=0,459$ & $\mathrm{p}=0,172$ & $\mathrm{p}=0,276$ \\
\hline
\end{tabular}


Tablo 3. Devam.

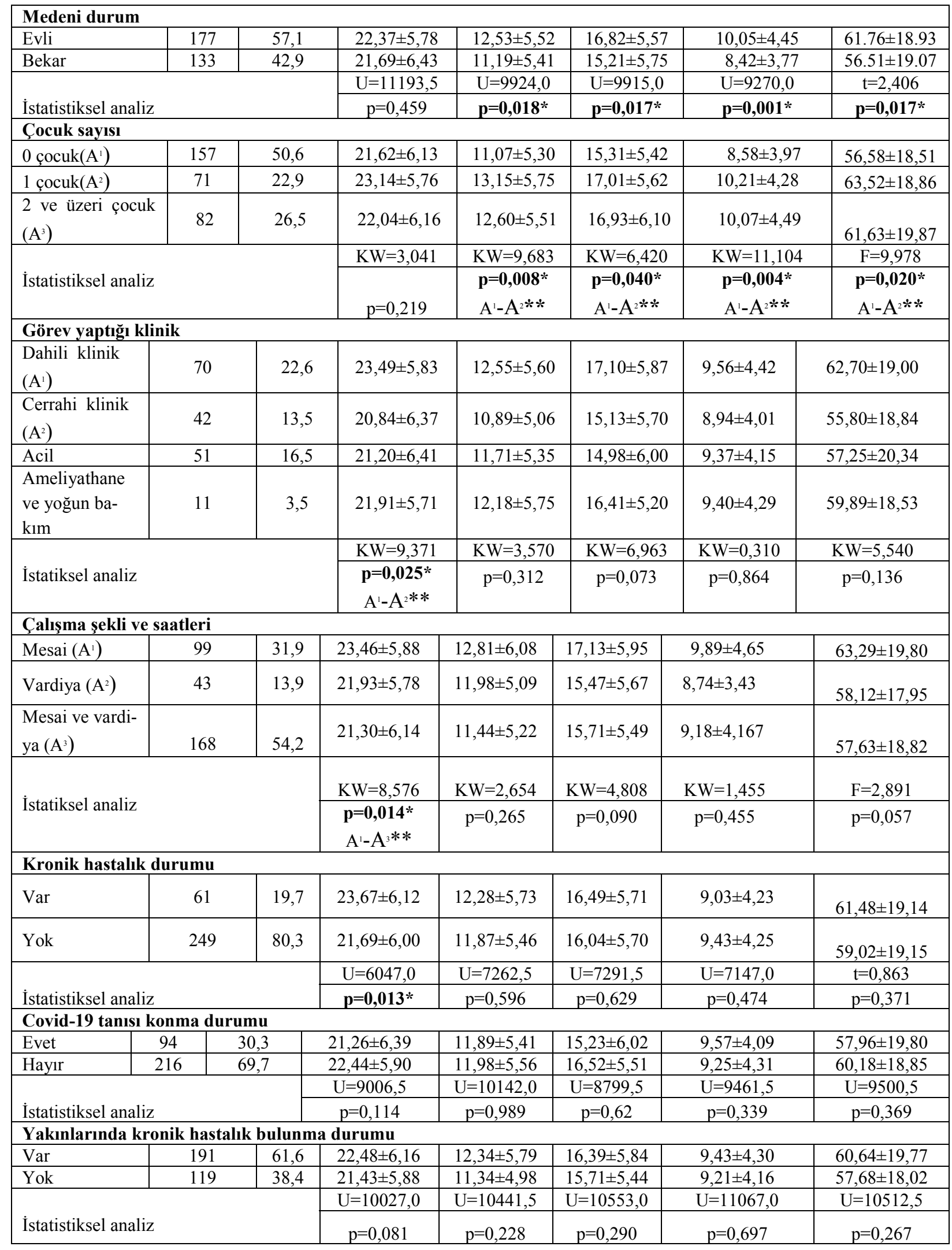


Tablo 3. Devam.

\begin{tabular}{|c|c|c|c|c|c|c|c|}
\hline \multicolumn{8}{|c|}{ Yakınlarında Covid-19 tanısı konma durumu } \\
\hline Evet & 153 & 49,4 & $22,77 \pm 6,37$ & $13,07 \pm 6,17$ & $16,78 \pm 5,96$ & $10,38 \pm 4,79$ & $63,00 \pm 21,10$ \\
\hline Hayır & 157 & 50,6 & $21,40 \pm 5,70$ & $10,86 \pm 4,54$ & $15,50 \pm 5,36$ & $8,34 \pm 3,35$ & $56,10 \pm 16,38$ \\
\hline \multirow{2}{*}{\multicolumn{3}{|c|}{ İstatistiksel analiz }} & $\mathrm{U}=10161,5$ & $\mathrm{U}=9765,5$ & $\mathrm{U}=10482,5$ & $\mathrm{U}=9226,5$ & $\mathrm{U}=9751,0$ \\
\hline & & & $\mathrm{p}=0,019 *$ & $\mathrm{p}=0,004 *$ & $\mathrm{p}=0,052$ & $\mathrm{p}=0,000 *$ & $\mathrm{p}=0,004 *$ \\
\hline \multicolumn{8}{|c|}{ Covid-19 aşısını yaptırma durumu } \\
\hline Yaptiran & 260 & 83,9 & $21,78 \pm 6,07$ & $11,90 \pm 5,51$ & $16,13 \pm 5,73$ & $9,47 \pm 4,31$ & $59,28 \pm 19,34$ \\
\hline Yaptırmayan & 50 & 16,1 & $23,60 \pm 5,87$ & $12,24 \pm 5,55$ & $16,12 \pm 5,57$ & $8,70 \pm 3,85$ & $60,66 \pm 18,21$ \\
\hline \multirow{2}{*}{\multicolumn{3}{|c|}{ İstatistiksel analiz }} & $\mathrm{U}=5359,5$ & $\mathrm{U}=6171,5$ & $\mathrm{U}=6456,0$ & $\mathrm{U}=5876,0$ & $\mathrm{t}=0,465$ \\
\hline & & & $\mathrm{p}=0,049 *$ & $\mathrm{p}=0,570$ & $\mathrm{p}=0,939$ & $\mathrm{p}=0,280$ & $\mathrm{p}=0,642$ \\
\hline \multicolumn{8}{|c|}{ Covid-19 sürecine bağlı olarak hemșirelik yapma isteği } \\
\hline İstiyorum & 113 & 36,5 & $24,37 \pm 5,51$ & $13,96 \pm 5,93$ & $17,92 \pm 5,38$ & $10,58 \pm 4,44$ & $66,84 \pm 18,40$ \\
\hline İstemiyorum & 197 & 63,5 & $20,76 \pm 5,99$ & $10,80 \pm 4,90$ & $15,10 \pm 5,63$ & $8,64 \pm 3,96$ & $55,30 \pm 18,31$ \\
\hline \multirow{2}{*}{\multicolumn{3}{|c|}{ İstatistiksel analiz }} & $\mathrm{U}=7121,0$ & $\mathrm{U}=7646,0$ & $\mathrm{U}=8018,5$ & $\mathrm{U}=8162,5$ & $\mathrm{t}=5,331$ \\
\hline & & & $\mathrm{p}=0,000 *$ & $\mathrm{p}=0,000 *$ & $\mathrm{p}=0,000 *$ & $\mathrm{p}=0,000 *$ & $\mathrm{p}=0,000 *$ \\
\hline
\end{tabular}

${ }^{*} \mathrm{p}<0.05$; **Dunn's procedure(fark); K19K-Ö: Koronofobi ölçeği; n: Sayı; \%: Yüzde; KW: Kruskal-Wallis; U: Mann-Whitney U; F: One-way Anova; p: Anlamlılık değeri; t: İndependent t testi; Ort: Ortalama; SS: Standart sapma.

evli hemşirelerde $12,53 \pm 5,52, \quad 16,82 \pm 5,57 \quad$ ve $10,05 \pm 4,45$ puan, bekar hemşirelerde ise $11,19 \pm 5,41,15,21 \pm 5,75$ ve $8,42 \pm 3,77$ puan olduğu görülmektedir. Gruplar arasındaki puanların istatistiki açıdan anlamlı farklılık oluşturduğu evlilerin bekarlara oranla yüksek puan aldığı tespit edildi $(\mathrm{p}<0,05$, Tablo 3$)$.

Hemşirelerin sahip olduğu çocuk sayısına göre K19K-Ö ve alt boyutları puan ortalamaları değerlendirildiğinde; K19K-Ö toplam puan ortalaması çocuğu olanlarda (1 çocuk: 63,52 $\pm 18,86,2$ çocuk: $61,63 \pm 19,87)$ çocuğu olmayanlardan $(56,58 \pm 18,51)$ daha yüksektir. Çocuğu olan hemşirelerin K19KÖ'nin somatik, sosyal ve ekonomik alt boyutu ortalama puanlarının çocuğu olmayan hemşirelere göre daha yüksek olduğu görülmektedir. Gruplar arasındaki puanların istatistiki açıdan anlamlı farklılık oluşturduğu saptandi $(\mathrm{p}<0,05$, Tablo 3$)$.

Araştırmada hemşirelerin görev yaptıkları kliniğe göre K19K-Ö ve alt boyutları puan ortalamaları incelendiğinde; K19K-Ö'nin psikolojik alt boyutu puan ortalaması dahili kliniklerde (kardiyoloji, dahiliye, palyatif bakım, nöroloji, intaniye, çocuk) çal1şan hemşirelerde $(23,49 \pm 5,83)$ cerrahi kliniklerde çalışan hemşirelerden $(20,84 \pm 6,37)$ yüksek bulundu. Gruplar arasındaki puanlarda istatistiksel olarak anlamlı bir farklılık olduğu belirlendi $(\mathrm{p}<0,05$, Tablo 3).

Hemşirelerin çalışma saatlerine göre K19K-Ö ve alt boyutları puan ortalamaları değerlendirildiğinde; K19K-Ö’nin psikolojik alt boyutu puan ortalamas1nın gündüz saatlerinde çalışan hemşirelerde $(23,46 \pm 5,88)$ diğer saatlerde çalışan hemşirelerden
$(21,30 \pm 6,14)$ yüksek olduğu görülmektedir. Gruplar arasındaki puanların istatistiki açıdan anlamlı farklılık oluşturduğu saptandı ( $<<0,05$, Tablo 3$)$.

Araştırmada hemşirelerin kendisinde kronik hastalık olması durumuna göre K19K-Ö ve alt boyutları puan ortalamaları incelendiğinde; K19K-Ö’nin psikolojik alt boyutu puan ortalaması kronik hastalığı olanlarda $23,67 \pm 6,12$, olmayanlarda ise $21,69 \pm 6,00$ 'dır. Gruplar arasındaki puanların istatistiki açıdan anlamlı farklılık oluşturduğu kronik hastalığı olanların olmayanlardan yüksek puan aldığı belirlendi $(\mathrm{p}<0,05$, Tablo 3).

Hemşirelerin yakın akrabalarına Covid-19 tanısı konma durumuna göre K19K-Ö alt boyutları puan ortalamaları değerlendirildiğinde; yakınına tanı konularda K19K-Ö toplam puan ortalaması $63,00 \pm 21,10 \quad \tan 1 \quad$ konulmayanlarda ise 56,10 $\pm 16,38$ 'dir. Yakınına Covid-19 tanısı konulan hemşirelerin K19K-Ö'nin psikolojik, somatik ve ekonomik alt boyutu ortalama puanlarının, yakınına Covid-19 tanısı konulmayan hemşirelere göre daha yüksek olduğu görülmektedir. Gruplar arasındaki puanların istatistiki açıdan anlamlı farklılık oluşturduğu tespit edildi ( $\mathrm{p}<0,05$, Tablo 3 ).

Hemşirelerin Covid-19 aşısı yaptırma durumlarına göre K19K-Ö alt boyutları puan ortalamaları ele alındığında; K19K-Ö’nin psikolojik alt boyutu puan ortalaması aşı yaptırmayan hemşirelerde $23,60 \pm 5,87$ aşı yaptıran hemşirelerde ise $21,78 \pm 6,07$ 'dir. Gruplar arasındaki puanların istatistiki açıdan anlamlı farklılık oluşturduğu aşı yaptırmayanların aşı yaptıranlara oranla yüksek puan aldığı belirlendi ( $p<0,05$, Tablo 3). 
Hemşirelerin Covid-19 sürecinde hemşirelik yapma isteğine göre K19K-Ö ve alt boyutları puan ortalamaları değerlendirildiğinde; K19K-Ö toplam puan ortalaması hemşirelik yapmak isteyenlerde $(66,84 \pm 18,40)$ hemşirelik yapmak istemeyenlerden $(55,30 \pm 18,31)$ daha yüksek olarak saptand1. K19KÖ'nin psikolojik, somatik, sosyal ve ekonomik alt boyutu ortalama puanlarının sırasıyla Covid-19 sürecinde hemşirelik yapmak isteyenlerde $24,37 \pm 5,51$, $13,96 \pm 5,93,17,92 \pm 5,38$ ve $10,58 \pm 4,44$ istemeyenlerde ise $20,76 \pm 5,51,10,80 \pm 4,90,15,10 \pm 5,63$ ve $8,64 \pm 3,96$ puan olduğu görülmektedir. Gruplar arasındaki puanların istatistiki açıdan anlamlı farklılık oluşturduğu hemşirelik yapmak isteyenlerin hemşirelik yapmak istemeyenlere oranla yüksek puan ald1ğ1 belirlendi ( $<<0,05$, Tablo 3$)$.

\section{TARTIŞMA VE SONUÇ}

Alan yazın incelendiğinde ülkemizde hemşirelerle yapılan çalışmalarda daha çok anksiyete, stres, depresyon, psikolojik sağlık ve refah üzerindeki sonuçlarına

odaklanıldığı görülmektedir. ${ }^{3}$ İlgili literatürde bu araştırmada kullanılan K19K-Ö ile hemşire popülasyonunda yapılan bir çalışma yoktur. Ancak toplumda koronofobi ile ilgili yapılan çalışma bulunmaktadır. ${ }^{9} \mathrm{Bu}$ araştırmadan elde edilen sonuçlar, hemşire popülasyonunda Covid-19 korkusunu değerlendiren benzer ölçeklerin kullanıldığı çalışmalardan elde edilen sonuçlarla karşılaştırılarak tartışıldı. ${ }^{1,15-17}$

Araştırmaya katılan hemşirelerin K19K-Ö toplam puan ortalaması $(59,51 \pm 19,14)$, ölçekten alınabilecek en düşük-en yüksek (20-100) puanla karşılaşt1rıldığında, hemşirelerde ortada bir düzeyde koronavirüs korkusu yaşadıkları söylenebilir. Hemşirelerin koronofobinin psikolojik boyutundan daha fazla etkilendikleri görülmektedir (Tablo 2). Ölçeğin geliştirildiği normal popülasyonda yapılan çalışmada K19K-Ö toplam puan ortalaması $65,42 \pm 14,09{ }^{\text {' }}$ dur. $^{9}$ Toplumda yapılan bir başka çalışmada koronafobinin orta seviyede olduğu belirtilmektedir. ${ }^{16}$ Çalışmalara göre hemşire popülasyonu ile normal popülasyon kıyaslandığında koronafobi düzeyinin benzer olduğu görülmektedir. Yine Filipinlerde hemşirelerle yapılan bir çalışmada hemşirelerin \%54,76'sında koronofobinin belirlenmesi, bu araştırma sonucu ile örtüşmektedir. ${ }^{15}$ Yapılan bir diğer çalışmada ise hemşirelerde covid-19 korkusunun topluma göre daha yüksek olduğu, korkuyu arttıran faktörün enfekte olma ve bilmeden diğerlerine bulaştırma riskinden kaynaklandığ belirtilmektedir. $^{12}$

Araştırmada kadın hemşirelerin psikolojik olarak daha fazla koronofobiden etkilendiği sonucuna varıld1 (Tablo 3). Koronafobi yüksek anksiyete seviyesi ile ilişkilendirilmektedir. ${ }^{1}$ Hemşirelerle yapılmış çalışmalarda yüksek anksiyete seviyesinin ${ }^{13,18-20}$ ve korkusunun $^{11}$ kadınlarda daha fazla olduğunu belirten çalışma sonuçları bu araştırma sonucunu desteklemektedir. ${ }^{13,18-20}$

Hemşirelerde medeni durumun ve çocuk sayısının koronafobiyi ve K19K-Ö'nin somatik, sosyal ve ekonomik alt boyutlarını etkilediği tespit edildi. Evli ve çocuklu olanların koronafobi puanı diğerlerinden daha yüksek bulundu (Tablo 3). Alan yazında evli ve çocuklu olan hemşirelerde anksiyetenin oldukça yüksek olduğunu ${ }^{13,21}$ ve evli hemşirelerde koronafobi düzeyinin yüksek olduğunu ${ }^{11}$ bildiren çalışmalar bu araştırma sonucuyla benzeşmektedir. Evli olan hemşirelerde iş yerinde uzun süreli çalışmak, çocuklarının evde kalmasıyla artan ebeveyn ev işi yükü, sürecin uzaması ve yaşamı en normal şekliyle sürdürmeye çalışmak kolay değildir. ${ }^{2,7,12} \mathrm{Hem}$ şirelerin; Covid-19 hastasına birebir bakım veren kişiler olması ile birlikte enfekte olma riski taşımalar1 K19K-Ö'nin somatik boyutunu, riskli grupta yer almaları sosyal açıdan dışlanmalarına neden olması K19K-Ö'nin sosyal boyutunu, artan iş yüküne karş1lık yeterli maddi desteğin alınmaması ise $\mathrm{K} 19 \mathrm{~K}$ Ö’nin ekonomik boyutunu neden etkilediğini açıklamaktadir.

Araştırmada dahili kliniklerde çalışan hemşirelerin diğer kliniklerde çalışan hemşirelere göre psikolojik olarak koronafobiden daha fazla etkilendikleri belirlendi (Tablo 3). Dahili kliniklerde çalışan hemşireler genellikle kronik hastalığı olan bireylere, yaşlılara ve çocuklara bakım vermektedirler. Bu hastaların bağışıklığının düşük olması, koronavirüs bulaştığında ölüm riskinin yüksek olması ve hastalığın hasarları dikkate alındığında araştırmada hemşirelerin enfekte olma ve bulaştırma korkusunu daha çok yaşadıkları ve psikolojik olarak etkilendikleri düşünülmektedir. Bahadır Yılmaz ve Yüksel'in yaptığı çalışmada yoğun bakım kliniklerinde çalışanların anksiyete düzeyinin diğer (dahili vs) kliniklerde çalışanlardan daha yüksek olduğu belirtilmektedir. ${ }^{13}$ Sonuçlar arasındaki farklılığın nedeni yapılan araştırmaların zamanlamasından ve Covid-19 tanılı hastaların yoğun bakımda tedavi görmesinden kaynaklanabilir. $\mathrm{Bu}$ araştırmanın yapıldığı döneminde aşılamanın başlamış olması, önceye oranla Covid-19 vakalarının azalması ve hastalık hakkında bilinenlerin artması sonuçları etkilemiş olabilir.

Araştırmada gündüz saatlerinde çalışan hemşirelerin, psikolojik olarak koronafobiden daha fazla etkilen- 
dikleri saptand1 (Tablo 3). Literatürde bu veriye benzer bir sonuçla karşılaşılamamıştır. Araştırmaya katılan gündüz saatlerinde çalışan hemşirelerin yaş ortalamasının daha yüksek, kadın, evli, çocuklu ve kronik hastalığı olabilme ihtimali olan hemşirelerden oluştuğu bilgisine dayanarak bu durumun sonucu etkilediği düşünülmektedir.

Kronik hastalığı olan hemşirelerin psikolojik olarak koronafobiden daha çok etkilendikleri belirlendi (Tablo 3). Mevcut kanıtlara göre koronavirüs, kronik hastalığ 1 olanlarda komorbiditeye neden olarak hastalığın şiddetini ve ölüm riskini arttırmaktadır. ${ }^{22}$ Pandemi sürecinin bire bir içinde yer alan bakım veren hemşirelerin koronavirüsün en yakın takipçisi olması kaçınılmazdır. Bu nedenle kronik hastalığı olan hemşirelerin psikolojik olarak etkilenmesi beklenen bir durumdur. Kronik hastalığı olan bireylerde koronavirüs korku ve kaygı düzeylerinin daha yüksek olduğunu bildiren çalışma sonuçları bu araştırma sonucuyla uyumludur. ${ }^{23,24}$

Araştırmada yakınına Covid-19 tanısı konulan hemşirelerin koronofobiden daha çok etkilendikleri, K19K-Ö’nin psikolojik, somatik ve ekonomik boyutları puanlarının yüksek olduğu görülmektedir (Tablo 3). Covid-19 hastalığı semptomatik olduğunda korunmak için önlemler almak daha kolaydır, fakat hastalığın asemptomatik seyrettiği durumlarda bulaşın önlenmesi kolay değildir. Enfekte olan yeni bireyin de hastalığı nasıl atlatacağı bilinmemektedir. $\mathrm{Bu}$ nedenle hemşireler bu süreci yönetirken hizmet sundukları bireyleri, kendilerini, ailelerini koruma ve baş etme konusunda güçsüz hissetmektedirler. ${ }^{25-27}$ Hemşireler mevcut sorumluluklarının yanında hasta olan yakınıyla ilgilenmek, hastalığa bağlı olumsuz duygularla başa çıkmak ve hasta olanın iş gücü kaybı nedeniyle ekonomik sorunlarla da karşılaştıklarında psikolojik olarak zorlanabilirler.

Hemşireler içerisinde aşı yaptırmayanların psikolojik olarak koronafobiden daha fazla etkilendikleri saptand1 (Tablo 3). Araştırmada aşı yaptırmayan hemşirelerin oranının \%16,1 olduğu görülmektedir. $\mathrm{Bu}$ hemşirelerin neden aşı yaptırmak istemedikleri sorgulanmamıştır ancak gebelik ( $\mathrm{n}=201, \% 12$ ile 24 gebe) gibi özel bir neden olabileceği gibi hastalığı atlatmış olmak $(\% 30,3)$ ya da aşının koruyuculuğuna olan güvensizlik olabilir. Sonuç olarak aşı yaptırmamak hastalığa yakalanabilme riskini arttırabileceğinden koronafobinin de artması beklenen bir durumdur.

Araştırmada Covid-19 sürecinde hemşirelik yapmak isteyen hemşirelerin K19K-Ö ve alt boyutları puanları yüksek bulundu (Tablo 3). Pandemi sürecinde hemşirelik yapmayı isteyen hemşireler $(\% 36,5)$ daha fazla koronadan korkmaktadır. Daha önceki çalışmalarda hemşirelerin yüksek derecede bulaşı olan hastalara bakma konusunda isteklerinin az olduğu belirtilmektedir. ${ }^{11,28} \mathrm{Bu}$ farklılı̆̆ın nedeni araştırmada hemşirelik yapma isteği Covid-19 hastasına bakma isteği olarak değil genel anlamda sorgulanmıştır. Hemşirelerin koronadan korksalar dahi işlerini isteyerek yapmaları dikkat çeken bir sonuçtur. Başka bir çalışmada hemşireler pandemide tüm korkulara rağmen hemşirelik yapmanın gurur verici, mesleki doyum sağlayan yüce bir deneyim olduğunu belirtmişlerdir. $^{29}$

Araştırmanın tek merkezli olarak yalnızca bir hastanede aktif çalışan hemşirelere uygulanmış olması çalışmanın sınırlılığı olduğundan sonuçlar da yalnızca bu hastanedeki hemşirelere genellenebilir. Başka bir sınırlama ilk aşılama fazı bittikten sonra ikinci aşılma fazının devam ettiği süreçte yapılması çalışma sonuçlarını etkileyebilir. Çünkü aşılama yapılması Covid-19 korkusunu azaltmış olabilir.

Sonuç olarak, kadın olma, dahili kliniklerde çalışıyor olma, mesai şeklinde çalışıyor olma, kronik hastalık varlığı, yakınının Covid-19 tanısı alması, aşılanma değişkenleri psikolojik olarak koronofobiyi etkilemektedir. Araştırmada evli ve çocuklu olan, yakınına Covid-19 tanısı konulan, Covid-19 sürecinde hemşirelik yapmak isteyen hemşirelerde K19K-Ö ve alt boyutları puanlarının yüksek olduğu belirlendi. Araştırma sonuçları hemşirelerde ruh sağlığını korumak için yapılabilecek yaklaşımlara katkı sağlayabilir. Bu sonuçlar doğrultusunda; pandeminin ruhsal, sosyal ve fiziksel sonuçlarına karşı hemşirelerin savunmalarını güçlendirmek için dijital platformlar kullanılarak psikoeğitime yönelik müdahalelerin yapılması, hemşirelerin risk grubunda olmalarından ötürü çalışan sağlığı güvenliğinin sağlanması ve sağlık taramalarının düzenli yapılması önerilmektedir.

Etik Komite Onayı: Çalışma için Ağrı İbrahim Çeçen Üniversitesi Bilimsel Araştırmalar Etik Kurulu'ndan etik onayı alındı (Tarih: 27.01.2021, karar no: 20).

Çıkar Çatışması: Yazarlar çıkar çatışması bildirmemişlerdir.

Yazar Katkılart: Fikir - BDG; Denetleme - BDG; Malzemeler - BDG; Veri toplanması ve/veya işlemesi - YS; Analiz ve/veya yorum - YS, BDG; Yaz1y1 yazan - BDG, YS

Hakem Değerlendirmesi: Dış bağımsız.

Diğer: Bu çalışma 5-6 Mart 2021 tarihleri arasında 
6. Çukurova Uluslararası Bilimsel Araştırmalar Kongresinde sözel bildiri olarak sunulmuştur.

\section{KAYNAKLAR}

1. Lee SA. Coronavirus Anxiety Scale: A brief mental health screener for Covid-19 related anxiety. Death Stud. 2020;44(7):393-401. doi:10.1080/07481187.2020.1748481

2. Çevik Aktura S, Özden G. Salgının psikolojik etkileri: Covid-19 hemşireleri. Uluslararası Sosyal Araştırmalar Dergisi. 2020;13(73):11461151.

3. Hiçdurmaz D, Üzar Özçetin YS. Covid-19 pandemisinde ön safta çalışan hemşirelerin ruhsal sağlığının korunması ve ruhsal travmanın önlenmesi. HUHEMFAD. 2020;7(Özel Say1):1-7. doi:10.31125/hunhemsire.775531

4. Catton H. Global challenges in health and health care for nurses and midwives everywhere. Int Nurs Rev. 2020;67(1):4-6. doi:10.1111/inr.12578

5. Ehrlich H, McKenney M, Elkbuli A. Protecting our healthcare workers during the Covid-19 pandemic. Am J Emerg Med. 2020;38(7):15271528. doi:10.1016/j.ajem.2020.04.024

6. Asmundson GJG, Taylor S. Coronaphobia: Fear and the 2019-nCoV outbreak. J Anxiety Disord. 2020. doi:10.1016/j.janxdis.2020.102196

7. Aslan R. Covid-19 fizyolojiyi ve psikolojiyi nasıl etkiliyor? Ayrıntı. 2020;8(88):47-53.

8. Tözun M, Babaoglu AB. Fobiler ve sağlıklı yaşam davranışları: Bir halk sağlığı bakışı. Fam Pract Palliat Care. 2016;1(1):24-26.

9. Arpacı İ, Karataş K, Baloğlu M. The development and initial tests for the psychometric properties of the Covid-19 Phobia Scale (C19P-S). Personality and Individual Differences. 2020. doi:10.1016 / j.paid.2020.110108

10. Kiyat İ, Karaman S, İşcan Ataşen G, Elkan Kiyat Z. Yeni koronavirüs (Covid-19) ile mücadelede hemşireler. THDD. 2020;1(1):81-90.

11. Labrague LJ, Alexis J, De Los Santos A. Associate professor prevalence and predictors of coronaphobia among frontline hospital and public health nurses. Public Health Nurs. 2020. doi:10.1111/phn.12841

12. Khattak SR, Saeed I, Rehman SU, Fayaz M. Impact of fear of Covid-19 pandemic on the mental health of nurses in Pakistan. J Loss Trauma. 2020. doi:10.1080 / 15325024.2020.1814580

13. Bahadir Yilmaz E, Yüksel A. State anxiety levels of nurses providing care to patients with Covid $\square$
19 in Turkey. Perspect Psychiatr Care. 2020. doi:10.1111/ppc.12661

14. Yazıcıoğlu Y, Erdoğan S. SPSS uygulamalı bilimsel araştırma yöntemleri. 2. Baskı. Ankara: Detay Yayıncılık; 2014.

15. Ahorsu DK, Lin CY, Imani V, Saffari M, Griffiths MD, Pakpour AH. The fear of Covid-19 scale: Development and initial validation. Int $\mathrm{J}$ Ment Health Addict. 2020. doi:10.1007/s11469020-00270-8

16. Gencer N. Pandemi sürecinde bireylerin koronavirüs (Covid-19) korkusu: Çorum örneği. USBAD. 2020;2(4):1153-1173. doi:10.47994/ usbad. 791577

17. Evren C, Evren B, Dalbudak E, Topcu M, Kutlu N. Measuring anxiety related to Covid-19: A Turkish validation study of the coronavirus anxiety scale. Death Stud. 2020. doi:10.1080/07481187.2020.1774969

18. Bitan DT, Grossman Giron A, Bloch Y, Mayer Y, Shiffman N, Mendlovic S. Fear of Covid-19 scale: Psychometric characteristics, reliability and validity in the Israeli population. Psychiatry Res. 2020. doi:10.1016 / j.psychres.2020.113100

19. Han L, Wong FKY, She DLM, et al. Anxiety and depression of nurses in a north west province in china during the period of novel coronavirus pneumonia outbreak. J Nurs Scholarship. 2020;52 (5):564-573. doi:10.1111/jnu.12590

20. Mora Magaña I, Lee SA, Maldonado Castellanos I, et al. Coronaphobia among healthcare professionalsin Mexico: A psychometric analysis, Death Stud. 2020. doi:10.1080 07481187.2020 .1808762

21. Sarıçam M. Covid-19 related anxiety in nurses working on front lines in Turkey. Nurs Midwifery Stud. 2020;9(3):178-181. doi:10.4103 / nms.nms_40_20

22. Çakır Kardeş V. Pandemi süreci ve sonrası ruhsal ve davranışsal değerlendirme. Türk Diyab Obez. 2020;2:160-169. doi:10.25048/tudod.754693

23. Bakioğlu F, Korkmaz O, Ercan H. Fear of Covid19 and positivity: Mediating role of intolerance of uncertainty, depression, anxiety, and stress. Int J Ment Health Addict. 2020. doi:10.1007/s11469 -020-00331-y

24. Özdin S, Özdin ŞB. Levels and predictors of anxiety, depression and health anxiety during Covid-19 pandemic in Turkish society: The importance of gender. Int J Soc Psychiatry. 2020;66 
(5):504-511. doi:10.1177/0020764020927051

25. Chen H, Guo J, Wang C et al. Clinical characteristics and intrauterine vertical transmission potential of Covid-19 infection in nine pregnant women: A retrospective review of medical records. Lancet. 2020;395(10226):809-815. doi:10.1016/ S0140-6736(20)30360-3

26. Liu Q, Luo D, Haase JE, et al. The experiences of health-care providers during the Covid-19 crisis in China: A qualitative study. Lancet Glob Health. 2020;8(6):790-800. doi:10.1016/ S2214109X(20)30204-7

27. Dönmez A, Canbulut N, Karaçam Z. Covid-19'lu bir ebenin klinik özellikleri ve deneyimleri: Olgu sunumu. HEAD. 2020;17(4):349-353. doi:10.5222/KUHEAD.2020.79926

28. Baduge MSP, Morphet J, Moss C. Emergency nurses' and department preparedness for an ebola outbreak: A (narrative) literature review. Int Emerg Nurs. 2020;38:41-49. doi:10.1016/ j.ienj.2017.12.002

29. Doğan S, Dayılar Candan H. Experiences of nurses working in Covid-19 services during the pandemic. Online International Conference of Covid -19, 12-14 June 2020, Istanbul/Turkey. 